Supporting Information for:

\title{
Optical Constants of Electrodeposited Mixed Molybdenum-Tungsten Oxide Films Determined by Variable Angle Spectroscopic Ellipsometry
}

\author{
R. Alan May, Lilia V. Kondrachova, Benjamin P. Hahn, Keith J. Stevenson* \\ Department of Chemistry and Biochemistry, \\ Center for Nano- and Molecular Science and Technology, Texas Materials Institute, \\ University of Texas at Austin, Austin, Texas 78712 \\ *Email: stevenson@mail.utexas.edu
}



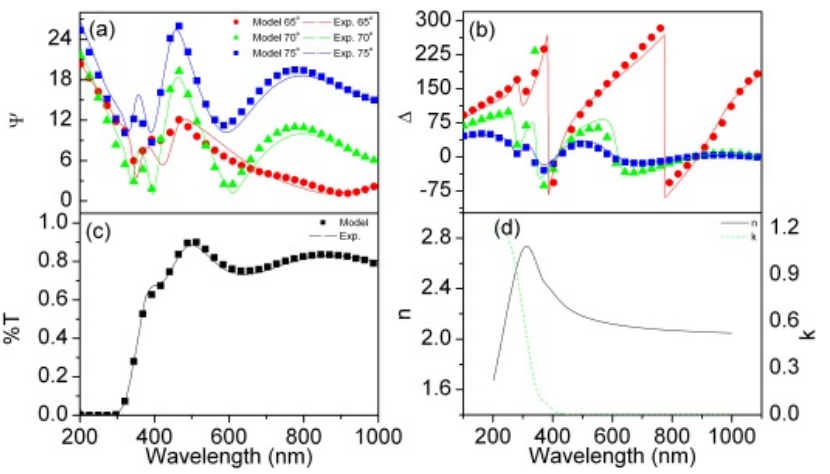

S1. (a) $\Psi$, (b) $\Delta$, and (c) $\% \mathrm{~T}$ versus $\lambda$ for experiment (line) and model fit (symbol) for $\mathrm{WO}_{3} \mathrm{~d}$ ) Estimated $\mathrm{n}$ and $\mathrm{k}$
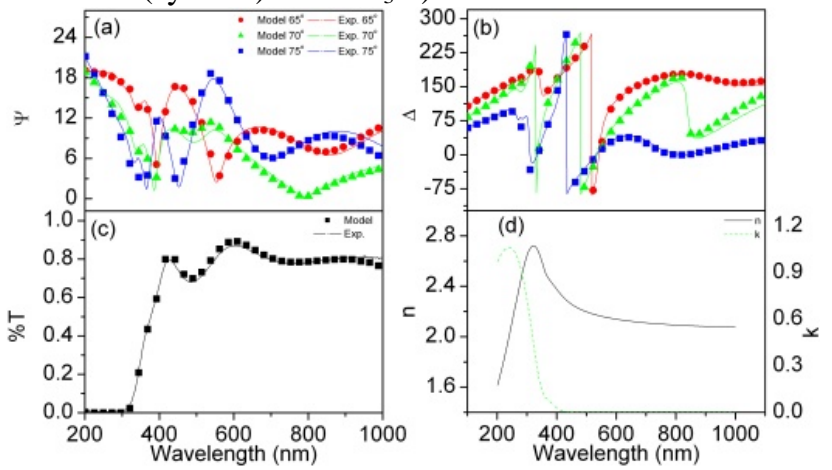

S3. (a) $\Psi$, (b) $\Delta$, and (c) $\% \mathrm{~T}$ versus $\lambda$ for experiment (line) and model fit (symbol) for $\mathrm{Mo}_{0.17} \mathrm{~W}_{0.83} \mathrm{O}_{3}$ d) Estimated $\mathrm{n}$ and $\mathrm{k}$
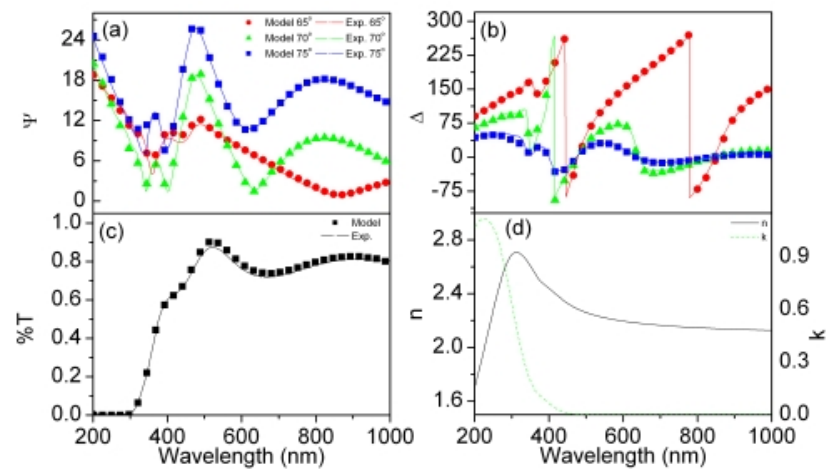

S5. (a) $\Psi$, (b) $\Delta$, and (c) $\% \mathrm{~T}$ versus $\lambda$ for experiment (line) and model fit (symbol) for $\mathrm{Mo}_{0.61} \mathrm{WO}_{0.39} \mathrm{O}_{3} \mathrm{~d}$ ) Estimated $\mathrm{n}$ and $\mathrm{k}$
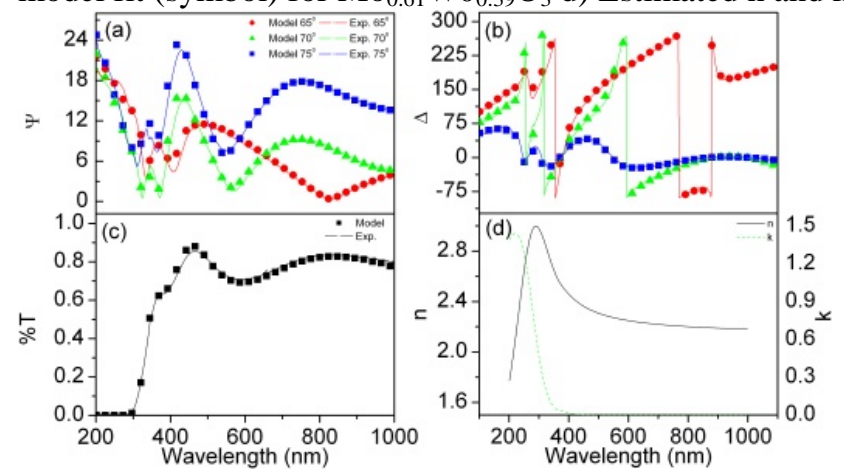

S7. (a) $\Psi$, (b) $\Delta$, and (c) $\% \mathrm{~T}$ versus $\lambda$ for experiment (line) and model fit (symbol) for $\mathrm{MoO}_{3} \mathrm{~d}$ ) Estimated $\mathrm{n}$ and $\mathrm{k}$
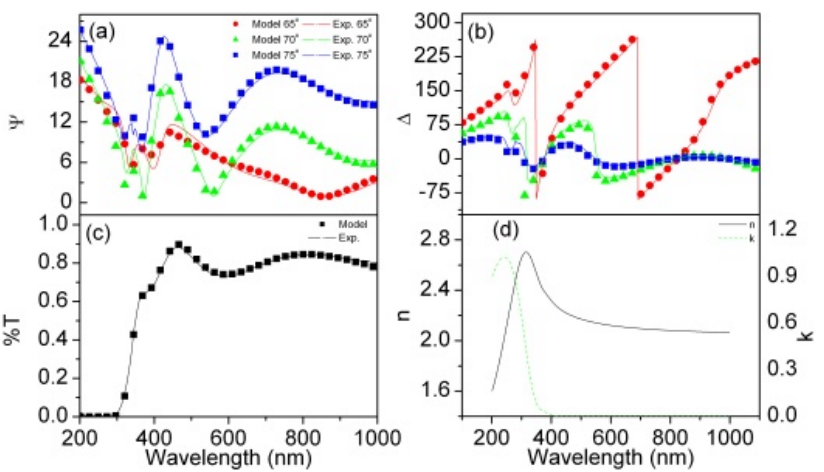

S2. (a) $\Psi$, (b) $\Delta$, and (c) $\% \mathrm{~T}$ versus $\lambda$ for experiment (line) and model fit (symbol) for $\mathrm{Mo}_{0.04} \mathrm{WO}_{0.96} \mathrm{O}_{3} \mathrm{~d}$ ) Estimated $\mathrm{n}$ and $\mathrm{k}$
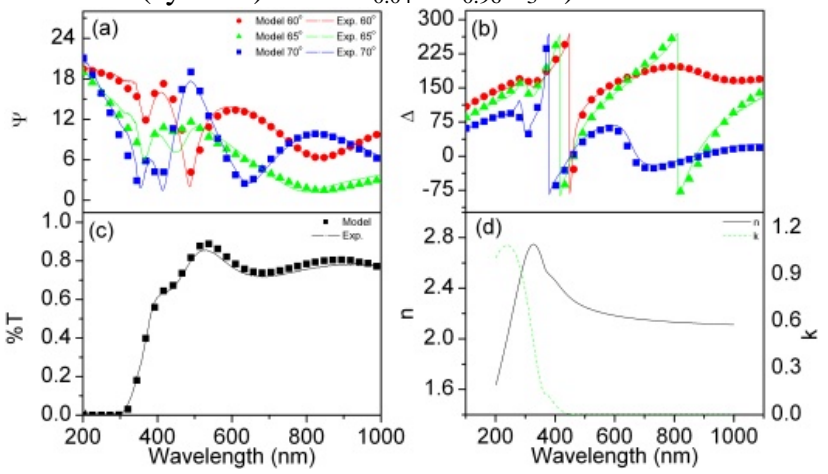

S4. (a) $\Psi$, (b) $\Delta$, and (c) $\% \mathrm{~T}$ versus $\lambda$ for experiment (line) and model fit (symbol) for $\mathrm{Mo}_{0.43} \mathrm{WO}_{0.57} \mathrm{O}_{3} \mathrm{~d}$ ) Estimated $\mathrm{n}$ and $\mathrm{k}$
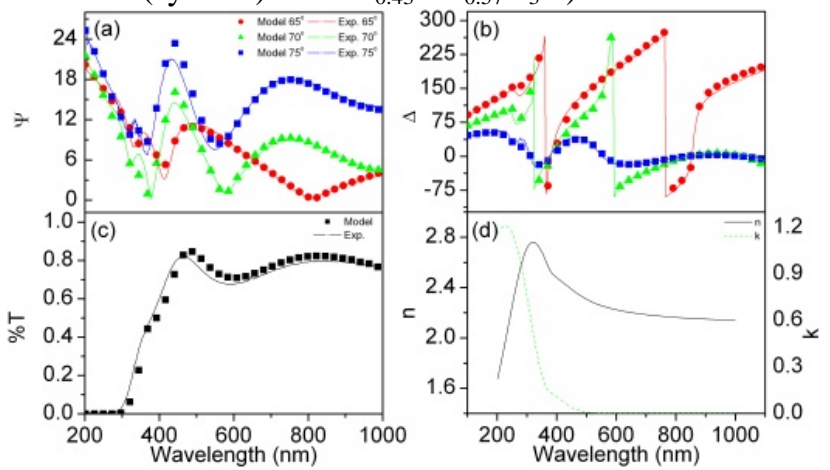

S6. (a) $\Psi$, (b) $\Delta$, and (c) $\% \mathrm{~T}$ versus $\lambda$ for experiment (line) and model fit (symbol) for $\mathrm{Mo}_{0.74} \mathrm{WO}_{0.26} \mathrm{O}_{3} \mathrm{~d}$ ) Estimated $\mathrm{n}$ and $\mathrm{k}$ 

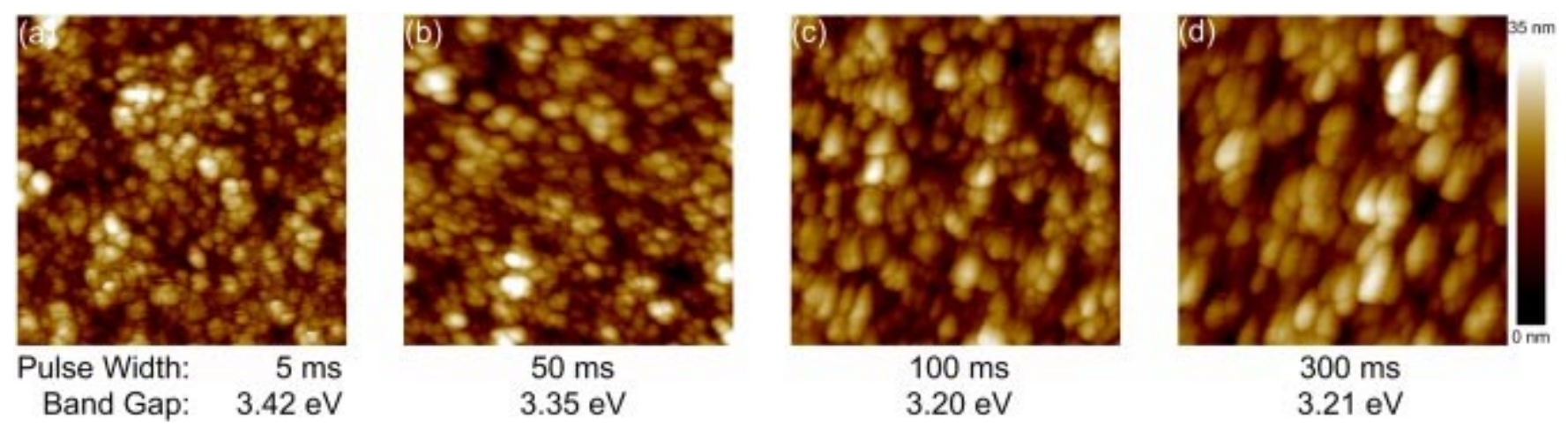

S8. $1 \times 1 \mu \mathrm{m}^{2}$ AFM topography images for $\mathrm{WO}_{3}$ films deposited with (a) $5 \mathrm{~ms}$ (b) $50 \mathrm{~ms}$ (c) $100 \mathrm{~ms}$ and (d) 300 ms pulse widths. 


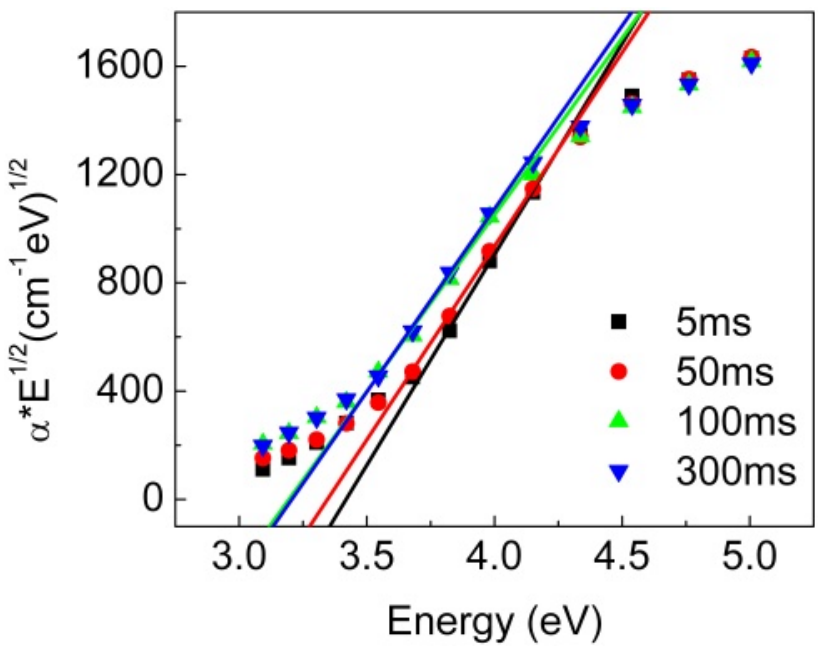

S9. Indirect Tauc plot used to derive the optical band gap of $\mathrm{WO}_{3}$ films prepared using various pulse widths (indicated on plot) to vary the grain size. 


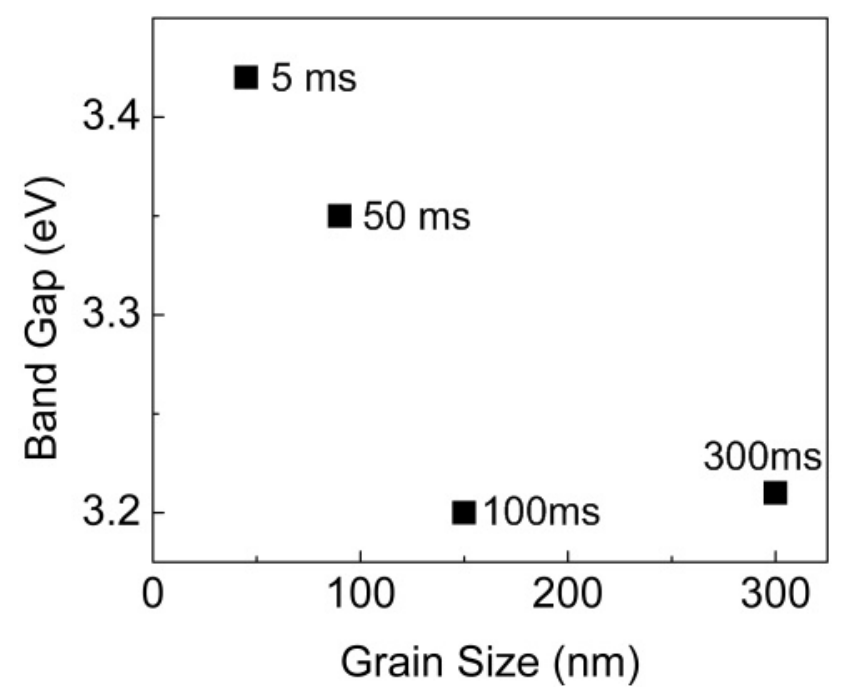

S10. Optical band gap of $\mathrm{WO}_{3}$ films versus grain size. The band gap decreases with grain size until the $300 \mathrm{~ms}$ film whose grains are too large to exhibit significant quantum size effects. 